biological therapy is an effective mean in increasing functional capacity and joint mobility, decreasing disease activity, improving quality of life for AS patients. Currently available data do not adequately address what role physiotherapy may have on patients with AS receiving biological drugs [1]. There are a few studies evaluating the effects of exercises in patients with AS receiving TNFa inhibitors [2,3]. References:

[1] Elyan M, Khan MA (2008) Does physical therapy still have a place in the treatment of ankylosing spondylitis? Curr Opin Rheumatol 20:282-286.

[2] Dubey SG, Leeder J, Gaffney K (2008) Physical therapy in anti-TNF treated patients with ankylosing spondylitis. Rheumatology (Oxford) 47:1100-1101.

[3] Lubrano E, D'Angelo S, Parsons WJ, Serino F, Tanzillo AT,Olivieri I, Pappone N (2006) Effects of a combination treatment of an intensive rehabilitation program and etanercept in patients with ankylosing spondylitis: a pilot study. $\mathrm{J}$ Rheumatol 33:2029-2034.

Disclosure of Interest: None declared

DOI: 10.1136/annrheumdis-2017-eular.5453

\section{AB1178 A PROSPECTIVE STUDY ON THE EFFECTS OF 3-MONTH COURSES OF TRADITIONAL PHYSIOTERAPY AND YOGA IN PATIENTS WITH CHRONIC ARTHRITIS AND PRIMARY FIBROMYALGIA}

C. Nalli ${ }^{1}$, L. Andreoli ${ }^{1}$, R. Avanzini ${ }^{2}$, P. Tipa ${ }^{2}$, M. Zanetti ${ }^{2}$, C. Milini ${ }^{3}$, S. Olivieri ${ }^{4}$, E. Abrami ${ }^{5}$, R. Furfari ${ }^{5}$, R. Gorla ${ }^{1}$, A. Tincani ${ }^{1} .{ }^{1}$ Rheumatology and Clinical Immunology Unit, Spedali Civili and University of Brescia; ${ }^{2}$ Physical Therapy Student, University of Brescia; ${ }^{3}$ Rehabilitation Unit, Spedali Civili; ${ }^{4}$ Accademia Essse: ${ }^{5}$ Associazione Bresciana Artrite Reumatoide (ABAR) Onlus, Brescia, Italy

Background: Physical activity is of fundamental importance for people with rheumatic diseases (RD). The traditional approach of Physiotherapy (PT) has been placed side by side with other physical programs, such as Yoga $(Y)$, aimed at reducing chronic pain and improving the quality of life.

Objectives: To evaluate the effects of PT and $Y$ on patients with inflammatory and non-inflammatory RD: Chronic Arthritis (CA) and Primary Fibromyalgia (FM). Methods: Patients were enrolled in a prospective study including 3 months of PT and 3 months of $Y$ (with a specific focus on the control of breathing Ai-jutsu). Each activity was performed bi-weekly in a dedicated facility. Patients were randomly allocated to either the group starting with PT or that starting with Y. After 3 months they switched to the other activity. At the beginning and at the end of each activity patients underwent a medical assessment of their physical status and were proposed questionnaires: 1) HAQ for disability in everyday life; 2) ZUNG self-rating depression scale; 3) Tampa scale for Kinesiophobia assessing the fear and avoidance of movement. Patients with FM compiled also the FIQ for the impact of FM in everyday life. All patients rated their physical pain by VAS (Visual Analogic Scale) from 0 to 10.

Results: Thirteen patients with CA ( $77 \%$ female, median age 62 years, median disease duration 19 years) and 8 with FM (100\% female, 56 years, 9 years) participated in the study. At baseline, there were no differences between CA and FM patients in terms of ZUNG, HAQ and Tampa scores. After 3 and 6 months of activity, all items had a tendency toward improvement, with a statistically significant reduction for VAS in both groups (nearly -30\%). By intra-group comparison between the beginning and the end of each activity, we observed that patients with CA had a significant reduction of ZUNG and HAQ scores (50 vs 40.5 and 0.600 vs 0.475 , respectively) during PT activity, while FM patients had a trend toward the increase of Tampa score (24.5 vs 34.5). During $Y$ activity, significant reductions were observed in VAS score for CA patients (5 vs 2.5) and in Tampa score for FM patients (34.5 vs 23.5). Overall, all items had a tendency toward improvement for FM patients during $\mathrm{Y}$ activity.

Conclusions: This pilot study involving both patients with inflammatory and noninflammatory RD demonstrated benefit from an integrated program of sequential PT and $Y$ and highlighted differences in patients' needs according to their disease type. Particularly, PT seemed to bring more benefit to CA patients, probably because of the individualized work on joint movement range and muscular strengthening, while FM patients may have had a negative impact by this approach, as seen by the increase in the fear of movement. Conversely, FM patients had a tendency toward improvement during $Y$ activity.

Acknowledgements: We thank the Patients Association (ABAR) for promoting and supporting the activities of this study and Essse Accademia for gently introducing our patients to the world of Yoga.

Disclosure of Interest: C. Nalli: None declared, L. Andreoli: None declared, R. Avanzini: None declared, P. Tipa: None declared, M. Zanetti: None declared, C. Milini: None declared, S. Olivieri Employee of: Accademia Essse, E. Abrami: None declared, R. Furfari: None declared, R. Gorla: None declared, A. Tincani: None declared

DOI: 10.1136/annrheumdis-2017-eular.4376

\section{AB1179 CAN THE PATIENTS WITH TOTAL KNEE ARTHROPLASTY ACHIEVE DISCHARGE CRITERIA FOR KNEE FLEXION}

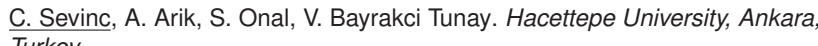
Turkey

Background: Knee range of motion (ROM) at discharge following total knee arthroplasty is used as a clinical indicator of performance. At least 90 degrees of flexion is standard discharge criteria for many hospitals.

Objectives: To investigate whether the discharge criteria is realistic in patients with TKA.

Methods: 13 patients ( $11=$ female, $2=$ male) who underwent unilateral TKA were included in this study. Mean age was $68.46 \pm 7.52$ years, mean body mass index (BMI) was $30.14 \pm 5.6 \mathrm{~kg} / \mathrm{m}^{2}$. Hospitalization duration was recorded. Knee flexion and extension degree were measured actively with goniometer during heel sliding on discharge day. Oxford Knee Score (OKS) was used to evaluate physical function and pain before surgery. Overall scores ranges from 0 (worst) to 48 (best). Descriptive statistics were used to analyse the data using SPSS v22.

Results: Hospitalization duration was $5.07 \pm 1.25$ days. Knee flexion degree and knee extension limitation were found $79.15 \pm 20.84^{\circ}$ and $12.92 \pm 7.31^{\circ}$, respectively. Oxford Knee Score was calculated $19 \pm 8.30$ point. Patients' results were given at Table 1.

Table 1. Patients' results

\begin{tabular}{lccc}
\hline Patients & Knee flexion degree $\left(^{\circ}\right)$ & Extension limitation $\left(^{\circ}\right)$ & Oxford Knee Score \\
\hline 1 & 65 & 11 & 28 \\
2 & 98 & 18 & 33 \\
3 & 94 & 12 & 15 \\
4 & 88 & 10 & 17 \\
5 & 100 & 24 & 22 \\
6 & 36 & 24 & 14 \\
7 & 86 & 12 & 15 \\
8 & 70 & 15 & 17 \\
9 & 90 & 2 & 12 \\
10 & 80 & 10 & 36 \\
11 & 42 & 10 & 12 \\
12 & 80 & 0 & 10 \\
13 & 100 & &
\end{tabular}

Conclusions: Patients have noticeable extension limitations at discharge. It should follow in the upcoming days. Nearly half of the patients flexed their knee less than expected. Due to the fact that discharge criteria for knee flexion is unrealistic. It should be investigate whether patients with less knee flexion degree can gain function as patients with more knee flexion degree.

\section{References:}

[1] Husted, Henrik, et al. Traditions and myths in hip and knee arthroplasty: A narrative review. Acta orthopaedica 85.6 (2014): 548-555.

[2] Naylor, Justine M., et al. Is discharge knee range of motion a useful and relevant clinical indicator after total knee replacement? Part 1. Journal of evaluation in clinical practice 18.3 (2012): 644-651.

Disclosure of Interest: None declared

DOI: 10.1136/annrheumdis-2017-eular.6397

\section{AB1180 THE INTENSIVE EXERCISE PROGRAMME FOR NON-RADIOGRAPHIC AXIAL SPONDYLOARTHRITIS AND FOR ANKYLOSING SPONDYLITIS MAY IMPROVED QUALITY OF LIFE AND DISEASE ACTIVITY}

M. Husakova ${ }^{1}$, K. Pavelka ${ }^{1}$, M. Spiritovic ${ }^{1,2}$, A. Levitova ${ }^{1,2}{ }^{1}{ }^{1}$ nstitute of Rheumatology and Department of Rheumatology, First Faculty of Medicine, Charles University, Prague 2; ${ }^{2}$ Charles University, Faculty of Physical Education and Sport, Prague, Czech Republic

Background: The therapy for axial spondyloarthritis (axSpA) is complex. Although anti-inflammatory medication is necessary for axSpA treament, the exercise therapy is required to maintain mobility. The limited data are available to evaluate the effect of exercise therapy on quality of life in axSpA, particularly in patients with the non-radiographic form of the disease (nr-axSpA).

Objectives: To investigated the quality of life in axSpA subgroups, nr-axSpA and Ankylosing spondylitis (AS) in response to intensive rehabilitation programme Methods: 46 patients with axSpA characterised according to criteria of Assessment of SpondyloArthritis international Society (ASAS) as nr-axSpA $(n=23)$ and AS $(n=23)$ with stable disease and treatment underwent 24 weeks long intervention. The intervention consisted in twice a week outpatient group physiotherapy as exercise units of 60 minutes and a daily home-based exercise programme. All outcomes, disease activity (Bath AS Disease Activity Index, BASDAI and AS Disease Activity Index, ASDAS-CRP) and quality of life (AS quality of life, ASQoL and European quality of life, EurQoL) as well as patients self-reported outcomes such as "patients global assessment" and "pain assessment" were measured at baseline and at the end of exercise program.

Results: Altogether, 41 axSpA patients (AS, $n=22$ and $n r-a x S p A, n=19$ ) finished complete six months programme. The disease activity was improved in all axSpA patients (ASDAS-CRP $2.08 \pm 0.12$ to $1.83 \pm 0.11, p<0.01$ ), particularly in $\mathrm{nr}$-axSpA subgroup, ASDAS-CRP $(1.98 \pm 0.19$ to $1.71 \pm 0.15, \mathrm{p}<0.05)$. There were no differences in the changes in ASDAS-CRP and BASDAl over the exercise training between groups (data not shown). After exercise therapy, positive changes of "Patients global assessment", were evaluated by patients of both subgroups, nr-ax-SpA $(33.42 \pm 5.13$ to $23.68 \pm 4.11, p<0.01)$ and AS $(35.22 \pm 3.94$ to $25.2 \pm 2.92$, $\mathrm{p}<0.01)$. The "assessment of pain during the last 7 days", however, was improved only by patients in the nr-axSpA subgroup $(34.74 \pm 5.88$ vs. $21.05 \pm 4.71, p<0.05)$. The quality of life, ASQoL was not changed after rehabilitation programme. 
The EurQoL was changed in all axSpA $(0.74 \pm 0.21$ to $0.77 \pm 0.18 p<0.05)$, but significantly was improved only in $\mathrm{nr}$-axSpA subgroup $(0.72 \pm 0.23$ to $0.78 \pm 0.18$, $p<0.01$ ), not AS. Similarly, the improvement of the assessment of "hodiernal health status" was found after an intervention only in the nr-axSpA subgroup (65.81 \pm 21.80 to $78.00 \pm 13.77, p<0.01)$.

Conclusions: Our study demonstrated beneficial effect of intensive exercise programme on disease activity and patients self-reported outcomes in $\mathrm{nr}$-axSpA and AS patients. The patients suffering from nr-axSpA can profit at least similarly from the rehabilitation care as those with radiographic form. The exercise programme should be recommended for both subtypes of axSpA.

\section{References:}

[1] Millner JR, et al. Exercise for ankylosing spondylitis: an evidencebased consensus statement. Semin Arthritis Rheum. 2016;45:411-27. doi: 10.1016/j.semarthrit.2015.08.003.

Acknowledgements: This study has been supported by the Project for Conceptual development for institution of Ministry of Health Czech Republic - Institute of Rheumatology (number 023728), by SVV for FTVS UK (number 2016-260346), GAUK (number 214615) and PRVOUK (number P38).

Disclosure of Interest: None declared

DOI: 10.1136/annrheumdis-2017-eular.2589

\section{AB1181 LOCAL STEIOD AND INSULIN INJECTION IN MANAGEMENT OF CARPAL TUNNEL SYNDROME; A COMPARATIVE STUDY}

M.H. Abu-Zaid, S. El morsy, S.A. Hablas. Rheumatology and Rehabilitation, Faculty of Medicine Tanta University Egypt, Tanta, Egypt

Background: Carpal tunnel syndrome (CTS) is the most common focal nerve entrapment; local corticosteroid (CS) injection has been widely used to treat CTS. Recently; Local insulin Injection in CTS has been studied as insulin has anti-inflammatory anti-edematous effects.

Objectives: To compare the effectiveness of local steroid and insulin injections in management of CTS

Methods: Forty patients complaining of mild or moderate idiopathic CTS (diagnosed clinically \& electrophysiologically and classified according to American association of neuromuscular diagnostic medicine monograph) divided into 2 equal groups.

Group I received two local injections of 10 IU NPH insulin into the affected carpal tunnel 2 weeks intervals. Group II: received single injection of triamcinolone acetonide $(20 \mathrm{mg} / 0.5 \mathrm{ml})$ all procedures done after informed consent. Patients with severe or secondary type of CTS were excluded from this study. Evaluation of the patients was done at baseline, 2 and 4 months later clinically by measuring visual analogue scale (VAS), Phallen and compression tests and electrophysiologically by measuring motor and sensory nerve conduction studies of median and ulnar nerves using a standardized technique.

Results: There was significant improvement in all clinical parameters in both groups after 2 and 4 months from injection $(p<0.01)$ including VAS, Phallen and compression tests with more improvement was noticed in group I. Also there was significant improvement in electrophysiological parameters such as distal motor latency (DML) and distal sensory velocity of median nerve 2 and 4 months after treatment $(p<0.01)$. However the improvement was more in group I but the difference between results in both groups were statistically nonsignificant.

Table 1. clinical and electrophysiological results

\begin{tabular}{|c|c|c|c|c|c|c|}
\hline & \multicolumn{2}{|c|}{ Before injection } & \multicolumn{2}{|c|}{ After 2 months } & \multicolumn{2}{|c|}{ After 4 months } \\
\hline & Group I & Group II & Group I & Group II & Group I & Group II \\
\hline VAS & $7.1 \pm 1.03$ & $7.25 \pm 1.377$ & $4.05 \pm 1.23$ & $5.107 \pm 1.57$ & $3.2 \pm 1.39$ & $3.75 \pm 1.878$ \\
\hline Positive Phallentest \% & 100 & 95 & 60 & 60 & 30 & 35 \\
\hline Positive compression & & & & & & \\
\hline test $\%$ & 100 & 100 & 60 & 65 & 30 & 30 \\
\hline DML (ms) & $4.61 \pm 0.34$ & $4.63 \pm 0.569$ & $4.375 \pm 0.37$ & $4.405 \pm 0.51$ & $4.15 \pm 0.14$ & $4.18 \pm 0.548$ \\
\hline $\begin{array}{l}\text { Distal median nerve } \\
\text { sensory velocity } \\
(\mathrm{m} / \mathrm{s})\end{array}$ & $32.9 \pm 5.32$ & $32.8 \pm 4.78$ & $36.9 \pm 6.21$ & $36.05 \pm 5.3$ & $39.9 \pm 5.39$ & $39.11 \pm 6.146$ \\
\hline
\end{tabular}

Conclusions: Local insulin injection is as effective as (or even better than) local steroid injection in management of CTS

References:

[1] Sun Q, Li J, Gao F. New insights into insulin: The anti-inflammatory effect and its clinical relevance. World J Diabetes. 2014 Apr 15; 5(2): 89-96.

[2] Ginanneschi F, Filippou G, Bonifazi M, Frediani B, Rossi A. Effects of Local Corticosteroid Injection on Electrical Properties of A $\beta$-Fibers in Carpal Tunnel Syndrome. J Mol Neurosci, 2014; 52:525-530.

[3] Ashraf A, Yazdani A, Mirshams S. Evaluation of the effectiveness of local insulin injection in type 2 diabetic patients with CTS. Electromyogr Clin Neurophysiol. 2009 May-Jun;49(4):161-6.

Acknowledgements: Thanks a lot to Dr. Samar Abd Alhamed for her great efforts in completing statistical analysis in this study.

Disclosure of Interest: None declared

DOI: 10.1136/annrheumdis-2017-eular.1215

\section{AB1182 THE ROLE OF VITAMIN D AND EXERCISES IN CORRECTION OF AGE-RELATED SKELETAL MUSCLE CHANGES IN POSTMENOPAUSAL WOMEN}

V. Povoroznyuk, N. Dzerovych, N. Balatska, A. Belinska, R. Povoroznyuk. D.F. Chebotarev Institute of Gerontology Nams Ukraine, Kyiv, Ukraine

Background: The aim of the study was to evaluate the role of vitamin $D$ and exercises in correction of age-related skeletal muscle changes in postmenopausal women.

Objectives: 38 postmenopausal women aged 53-82 years (mean age $67.00 \pm 7.08 \mathrm{yrs}$; mean height $-160.31 \pm 6.83 \mathrm{~cm}$; mean weight $-63.25 \pm 8.59$ $\mathrm{kg}$, body mass index $-24.62 \pm 3.09 \mathrm{~kg} / \mathrm{m}^{2}$ ) were examined. All subjects were free of systemic disorders (endocrine, renal, hepatic etc.) and did not take any medications known to affect skeletal and muscle metabolism. The women were divided into the following groups: A - control group $(n=10)$, B - women who took an individually-targeted vitamin D therapy $(n=11), C$ women who took an individually-targeted vitamin D therapy and OTAGO Exercise Programme (http://www.hfwcny.org/Tools/BroadCaster/Upload/Project13/ Docs/Otago_Exercise_Programme.pdf) during 12 months.

Methods: The assessment of the examined women was conducted every 3 months at the medical center. We used the following questionnaires: SARC-F, IADL-questionnaire, frailty scale, Desmond fall risk questionnaire. For evaluation of skeletal muscle function and strength, we assessed the usual gait speed and used hand dynamometry. 25(OH)D total and iPTH levels were measured by electrochemiluminescent method i.e. Elecsys 2010 analytical system (Roche Diagnostics, Germany) and test-systems cobas. The lean mass was measured by the DXA method (Prodigy, GEHC Lunar, Madison, WI, USA). "Statistika 6.0" ${ }^{(}$ StatSoft, Inc. was used for the data processing purposes.

Results: At the baseline, the groups of examined women did not differ in their age, anthropometric characteristics, $25(\mathrm{OH}) \mathrm{D}$ values, data of skeletal muscle mass, strength and function. In women of the control group, the mean $25(\mathrm{OH}) \mathrm{D}$ level significantly increased after 9 months of observation ( 9 months $-p=0.03$ ) purportedly due to the seasonal factors. In women of 2nd and 3rd groups, the 25(OH)D level significantly increased after 3, 6, 9 and 12 months of observations (2nd group: 3 months $-p=0.009,6$ months $-p=0.007,9$ months $-p=0.005,12$ months $-p=0.003$; 3rd group: 3 months $-p<0.001,6$ months $-p<0.001,9$ months $-p<0.001,12$ months $-p<0.001)$. The data of SARC-F, IADL-questionnaires did not change during 12 months of observation in women of 1 st and 2nd groups; however, in the 3rd group the SARC-F data significantly decreased after 12 months $(p=0,02)$ while the IADL data - significantly increased after $9(p=0.04)$ and 12 months $(p=0.05)$. The data of frailty scale and Desmond fall risk questionnaire did not differ in all groups during 12 months. The muscle strength significantly increased after 9 months $(p=0.01)$ in women of 3rd group while in women of 1st and 2nd group this parameter did not change. The usual gait speed and lean mass assessed by DXA did not change in all groups during 12 months. The fall frequency in women of 1 st group significantly increased after 12 months, in women of 2 nd group it did not change while in women of 3rd group the fall frequency significantly decreased.

Conclusions: Using individually-targeted vitamin D therapy and OTAGO Exercise Programme during 12 months significantly improves daily activity, muscle strength and decreases the fall frequency in postmenopausal women.

Disclosure of Interest: None declared

DOI: 10.1136/annrheumdis-2017-eular.5898

\section{Education}

\section{AB1183 PATIENT'S EDUCATION IN THE ADMINISTRATION OF SUBCUTANEOUS DRUGS IN THE RHEUMATOLOGY DAY-CARE HOSPITAL UNITS}

A. Erra, A. Fagil, L. López. Rheumatology, Hospital San Rafael, Barcelona, Spain

Background: Rheumatology Day-Care Hospital Unit (DHU) is defined as a hospital care for a few hours with the objective to do diagnosis, clinical trials and/or multiple test, patient education and treatments that cannot be done in the outpatient clinic, but which do not justify the complete stay in the hospital

Objectives: Analyze the number of visits that one patient needs in the Rheumatology-DHU to learn the self-administration of a subcutaneous drug.

To evaluate if there are differences between the numbers of visits made in Rheumatology-DHU for the different drugs, and between the different age groups of the patients.

Methods: All patients who were prescribed a subcutaneous drug (except denosumab) during the period January 2015 - December 2016 were referred to Rheumatology-DHU. The nurse gave instructions, she supervised the patient's learning and she decided if the patients needed a new control in RheumatologyDHU.

The following data were recorded: sex, age, diagnosis, drug, number of visits each patient made in Rheumatology-DHU, reason for new visit to Rheumatology-DHU in patients who had already been discharged and adherence to treatment.

Results: 101 patients were visited in Rheumatology-DHU (8 were referred twice for education of different drugs). 79 were women (78\%) and 22 men (22\%). Mean age (MA) of $65+/-17$ years (SD). 